\title{
Detection of nucleic acid of classical swine fever virus by reverse transcription loop-mediated isothermal amplification (RT-LAMP)
}

\author{
Kanokwan Wongsawat ${ }^{1}$, Tararaj Dharakul ${ }^{2}$, Phairot Narat ${ }^{3}$, Jundee Rabablert $^{1^{*}}$ \\ ${ }^{1}$ Department of Biology, Faculty of Science, Silpakorn University, Nakhon Pathom, Thailand; \\ *Correspondence author: jundee@su.ac.th \\ ${ }^{2}$ Department of Immunology, Faculty of Medicine, Siriraj Hospital Mahidol University, Bangkok, Thailand; \\ ${ }^{3}$ Bangkok Agro-Industrial Products Public Co., Ltd., Bangkok, Thailand.
}

Received 2 May 2011; revised 31 May 2011; accepted 27 June 2011.

\begin{abstract}
Classical swine fever virus (CSFV) is the causative agent of Classical swine fever which is a highly contagious disease affecting swine and resulting in severe economic losses. In this study, we developed reverse transcription loopmediated isothermal amplification (RT-LAMP) assay targeting the 5'UTR gene for the detection of CSFV. This amplification method can be obtained in $1 \mathrm{~h}$ under isothermal conditions $\left(65^{\circ} \mathrm{C}\right)$ employing a set of six specific primers mixtures. Amplification product was visualized by using hydroxynaphthol blue (HNB) dye and agarose gel electrophoresis. The sensitivity was 100 copy numbers. No cross-reactivity related to Japanese encephalitis virus (JEV) and porcine reproductive and respiratory syndrome virus (PRRSV) was demonstrated. The results demonstrated that the RT-LAMP assay is a useful tool for the rapid and sensitive for CSFV detection in swine.
\end{abstract}

Keywords: Classical Swine Fever Virus (CSFV); RT-LAMP; Hydroxynaphthol Blue Dye

\section{INTRODUCTION}

Classical swine fever (CSF) is a highly contagious disease affecting swine, resulting in severe economic losses [1]. Classical swine fever virus (CSFV), the causative agent of CSF is a member of the genus Pesti- virus within the Family Flaviviridae [2]. CSFV is a small, enveloped virus with a $12.5 \mathrm{~kb}$; positive sin- gle-stranded RNA genome containing a single, large open reading frame (ORF) flanked bytwo highly conserved untranslated regions (UTR) at the 5' and 3 'ends. The
5'UTR functions as an internal ribosomal entry site for translation initiation of the pre-polyprotein and genome replication [3]. The host range of CSFV is narrow; this virus is restricted to its natural hosts, domestic pigs and feral pigs. The control of CSF is based on stamping out policies and/or on vaccination. However, failed immunization against CSF has been reported, mainly due to interference from maternal antibodies and other infections $[4,5]$.

In Thailand, CSF was first reported in 1950 at Bangkhen area in Bangkok. It was declared a notifiable disease in 1954 up to date; it has gradually become enzootic. [6]. The disease is generally subject to statutory control, involving slaughter of affected pig herds and restrictions on movements of pigs and pig products from affected regions [2]. Although eradicated from many countries, CSF continues to cause serious problems in different parts of the world [7]. Rapid and accurate diagnosis is the key factor for the control of CSF. The diagnosis based on clinical signs is often difficult, because clinical signs are rather variable and may be mistaken for other febrile and/or haemorrhagic diseases of pigs, essentially African swine fever [8]. Rapid, accurate, and pre-clinical laboratory diagnosis of CSFV is therefore a matter of urgency in order to prevent and control the epidemics. Current laboratory diagnoses of CSFV rely on virus isolation, serological methods, detection of antigen and nucleic acid amplification [9-12]. The PCRbase procedures are generally considered to be the most sensitive in vitro method for detecting CSFV infection. However, these techniques require centralized laboratory facilities and clinical specimen submissions.

Loop-mediated isothermal amplification (LAMP) is a nucleic acid amplification method developed by Notomi et al. [13] The benefits of LAMP compared with other nucleic acid amplification techniques is an easy opera- 
tion, no need for special equipment, superior sensitivity and speed, low contamination risk, and suitability for high-throughput DNA detection. Additionally, LAMP products can be observed by the naked eye when a white precipitate of magnesium pyrophosphate is present in the reaction mixture [14]. However, this detection is limited when the turbidity of reaction is low. To increase the sensitivity, LAMP products stained with ethidium bromide were used [15]. Unfortunately, the product of detection system with ethidium bromide has several limitations, such as generation of hazardous waste and less sensitivity than that of SYBR Green. Therefore, many investigators have developed RT-LAMP to be visualized by naked eye and with SYBR Green for DNA detection [16].

Reverse transcription loop-mediated isothermal amplification (RT-LAMP) was used as tool for amplification and has emerged as a powerful gene amplification tool due to its simplicity, speed, specificity and costeffectiveness. This technique is being used increasingly for rapid detection and typing of emerging viruses such as Severe acute respiratory syndrome coronavirus [17], Japanese encephalitis virus [18], Pseudorabies virus [19] and Classical swine fever virus [20]. Rapid and costeffective RT-LAMP assays for the pre-clinical detection of CSFV visualized directly with the naked eye by addition of SYBR Green have been described [20-22]. SYBR Green is an intercalating agent binding with doublestranded DNA; thus a disadvantage of SYBR Green is that it is equally incorporated into every amplicon. Should unspecific sequences be amplified, the measured signal would correspond to both non-specific and specific products [23]. It has been reported that hydroxynaphthol blue (HNB) was used as a colorimetric indicator for the titration of calcium ion and magnesium ion [24]. In addition, the sensitivity of LAMP assay using HNB was equivalent to that of the assay using SYBR Green [25]. Therefore, this colorimetric assay is suitable not only for laboratory research but also for clinical diagnoses of many infectious diseases.

In the present study, we developed RT-LAMP determined by hydroxynaphthol blue (HNB) dye-mediated visualization using the naked eye. The high sensitivity and specificity of the RT-LAMP reaction were due to continuous amplification under isothermal conditions. This assay employed six primers that recognized eight distinct regions of the 5'UTR gene from CSFV.

\section{MATERIALS AND METHODS}

\subsection{Design of CSFV-Specific Primers}

Nucleic acid sequences of different CSFV were obtained from GenBank and aligned with using the CLU-
STALW multiple sequence alignment programs. The conserved fragment was chosen to be the target region, which was used to design CSFV primers for RT-LAMP and RT-PCR by the Primer Explorer V4 software program and Primer3 Input (version 0.4.0) program, respecttively. All oligonucleotide primers were customary synthesized by Bio Basic Inc. (East Markham, Ontario, Canada).

\subsection{Viruses and Vaccines}

The CSFV Bangkhen strain as reference strain, obtained from Department of Livestock Development, Ministry of Agriculture and Cooperatives, was used as the viral nucleic acid/positive standard in the assay system employed in this study. The other strains included Japanese encephalitis virus (JEV), cultured at Department of Biology, Faculty of Science, Silpakorn University. Hog-cholera tissue culture live vaccine (LPC-PRK strain) was purchased from Formosa Biomedical Inc. (Taiwan) and provided as 10 vaccine doses per vial of which each dose contained tissue culture of Hog-cholera virus fluid at least $10^{3.5} \mathrm{RID}_{50}$ (Rabbit Infectious Doses). Porcine reproductive and respiratory syndrome virus (PRRSV) modified live vaccine was purchased from USA. All viruses and vaccines were identified by conventional RT-PCR.

\subsection{RNA Extraction}

The spleen from swine infected with CSFV Bangkhen strain was harvested and homogenized with PBS pH 7.4. The cell pellet was centrifuged at $400 \mathrm{~g}$ for $10 \mathrm{~min}$ at $4^{\circ} \mathrm{C}$. Total RNA was extracted from the suspension with QIAmp viral RNA mini kit (Qiagen, Germany) according to the manufacturer's instruction. After elution, the RNA sample was stored at $-80^{\circ} \mathrm{C}$ until required.

\subsection{RT-PCR}

The amplification 5'UTR gene of CSFV was performed by using a QIAGEN OneStep RT-PCR kit (Qiagen, Germany) according to the manufacturer's instruction. The thermal profile of RT-PCR was $50^{\circ} \mathrm{C}$ for $30 \mathrm{~min}$ and $95^{\circ} \mathrm{C}$ for $15 \mathrm{~min}$, followed by 30 cycles of $94^{\circ} \mathrm{C}$ for $1 \mathrm{~min}, 52^{\circ} \mathrm{C}$ for $1 \mathrm{~min}$, and $72^{\circ} \mathrm{C}$ for $1 \mathrm{~min}$ and a final extension cycle at $72^{\circ} \mathrm{C}$ for $10 \mathrm{~min}$. After amplification, the PCR products were stored overnight at $2^{\circ} \mathrm{C}$ $-8^{\circ} \mathrm{C}$ until required and were analyzed by $1 \%$ of agarose gel electrophoresis.

\subsection{Recombinant Plasmid Construction}

The 445-bp amplicon was purified using a QIAquick Gel Extraction kit (Qiagen, Germany) and cloned into 
the pGEM-T easy vector system I (Promega, Madison, Wis.) according to the manufacturer's specifications. The recombinant plasmid was transformed into $E$. coli DH5 $\alpha$ cells followed by blue-white colony selection. The white colonies were picked and inoculated into LB broth and incubated at $37^{\circ} \mathrm{C}$ overnight with horizontal shaking. Plasmid DNA was extracted from the culture with the QIAprep Spin Miniprep kit (Qiagen, Germany) as followed manufacture's instructions and checked for DNA insertion by a vector-specific restriction enzyme digestion (EcoRI and $\underline{N C O I}$ ). The digested products were UV visualized by $1 \%$ of agarose gel electrophoresis after stained with ethidium bromide. Plasmid was diluted to determine the sensitivity of RT-LAMP assays.

\subsection{RT-LAMP Assay}

The RT-LAMP reaction was carried out in a total volume of $25 \mu \mathrm{L}$, with mixture of $1 \times$ Thermo buffer (New England Biolabs Inc., Beverly, MA, USA) contained $20 \mathrm{mM}$ Tris- $\mathrm{HCl}$ (pH 8.8), $10 \mathrm{mM} \mathrm{KCl}, 10 \mathrm{mM}\left(\mathrm{NH}_{4}\right)_{2} \mathrm{SO}_{4}, 8 \mathrm{mM}$ $\mathrm{MgSO}_{4}$ and $0.1 \%$ Triton X-100, $0.8 \mathrm{M}$ betaine (Sigma-Aldrich, USA), $1.0 \mathrm{mM}$ dNTP mix (Promega, Madison, WI, USA), 8 U Bst DNA polymerase (large fragment; New England Biolabs Inc., Beverly, MA, USA), $5 \mathrm{U}$ AMV reverse transcriptase (Promega, Madison, WI, USA), $0.2 \mu \mathrm{M}$ each of primers CSUF3 and CSUB3, 1.6 $\mu \mathrm{M}$ each of primers CSUFIP and CSUBIP, $8 \mu \mathrm{M}$ each of primers ULF and ULB, $4.5 \mu \mathrm{L}$ of template RNA. The mixture was incubated at $65^{\circ} \mathrm{C}$ for $60 \mathrm{~min}$, and then heated at $80^{\circ} \mathrm{C}$ for $3 \mathrm{~min}$ to stop the reaction.

\subsection{Monitoring of RT-LAMP Amplification}

1) Analyzation by agarose gel eletrophoresis. After amplification, the $2 \mu \mathrm{L}$ aliquots of RT-LAMP products were UV visualized by $1 \%$ of agarose gel electrophoresis after stained with ethidium bromide

2) Visualization by the naked eye. The inspection for amplification was also performed through observations of color change following the addition of $120 \mu \mathrm{M}$ hydroxynaphthol blue (HNB) dye (Sigma-Aldrich, USA) to the tube. The positive amplification was indicated by a color change from violet to sky blue. Negative amplification was retained of violet.

\subsection{Sensitivity of CSFV RT-LAMP Assay}

The sensitivity was determined by testing serial 10 -fold dilutions of a cloned target. The template over a range of $10^{6}$ to 10 copy numbers was obtained. The RNase free water was used as the negative control. The RT-LAMP amplification product was analyzed by agarose gel eletrophoresis and naked eye.

\subsection{Specificity of CSFV RT-LAMP Assay}

RNA was extracted from Hog-cholera live vaccine, JE virus and modified live PRRS vaccine with QIAmp viral RNA mini kit (Qiagen), according to the manufacturer's instruction. After elution, RNA samples were used as template in the specificity test of this assay. Hog-cholera live vaccine was used as positive control. The RNase free water was used as the negative control. After amplification, the RT-LAMP product was analyzed by agarose gel eletrophoresis and naked eye.

\section{RESULTS}

\subsection{Designing the CSFV-Specific Primers}

In this study, the 5'UTR gene which showed highly conserved regions was selected as the target sequence for designing primers RT-LAMP and RT-PCR. The RTLAMP primers, a set of six primers comprising two outer primers were described as being forward outer primer (CSUF3) and backward outer primer (CSUB3). The inner primers were described as being forward inner primer (CSUFIP) and backward inner primer (CSUBIP). Furthermore, two loop primers, viz, forward loop primer (ULF) and backward loop primer (ULB) that recognized eight distinct regions on the target sequence. The primers were selected based on criteria described previously by Notomi et al. [13]. The RT-PCR primer comprised of forward (CSU1) and reverse (CSU2) primers.

\subsection{RT-PCR Product}

The RT-PCR product was generated by employing the CSU1 and CSU2 primers targeting the 5'UTR gene of CSFV. The target was amplified by using one step RT-PCR, reverses transcription and PCR carried out sequentially in the same tube. After amplification, the PCR product was analyzed by agarose gel eletrophoresis. For positive, the RT-PCR product size was 445 bp (Figure 1).

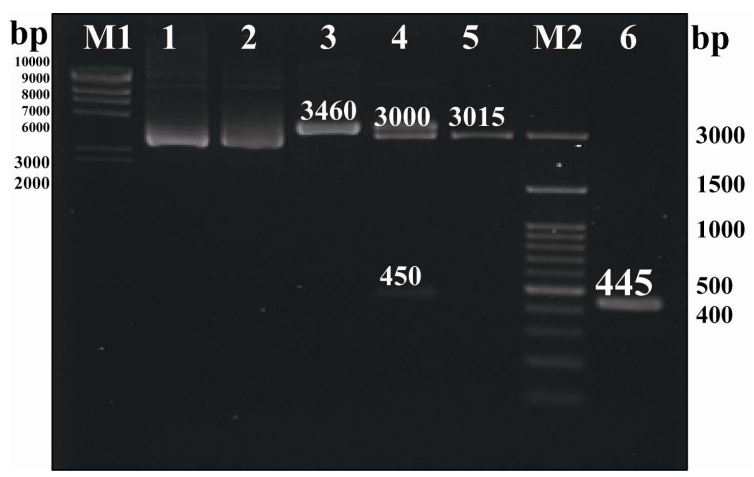

Figure 1. The size of recombinant plasmid compared with plasmid control after being cut with restriction enzymes as observed from gel electrophoresis relied. 


\subsection{Recombinant Plasmid Construction}

The white colonies were picked and detected by restriction enzyme digestion NcoI or EcoRI. The recombinant plasmid was digested with NcoI for 1 site cutting. The DNA pattern was shown one band at size of approximately $3460 \mathrm{bp}$ (molecular weight of CSFV-5'UTR DNA and pGEM-T easy vector were $445 \mathrm{bp}$ and $3015 \mathrm{bp}$, respectively). The recombinant plasmid was digested with EcoRI for 2 sites cutting. The DNA patterns were shown two bands of approximately $450 \mathrm{bp}$ and $3000 \mathrm{bp}$ (5'UTR DNA and pGEM-T easy vector, respectively). The assay detected CSFV revealed molecular weight size was $445 \mathrm{bp}$, as observed from gel electrophoresis (Figure 1).

\subsection{Sensitivity of RT-LAMP Assay}

The sensitivity of RT-LAMP assay for the detection of CSFV was determined with serial dilutions of a recombinant plasmid. The template was ranging from $10^{6}$ to 10 copy numbers. The assay detected at least 100 copy numbers, showing the characteristic ladder-like pattern in the gel (Figure 2) and visualized directly with the naked eye by addition of hydroxynaphthol blue (HNB) dye, showing color changes from violet to sky blue (Figure 3). For negative control, the RNase free water did not show either ladder-like pattern in the gel (Figure 2) or color change of HNB dye (Figure 3).

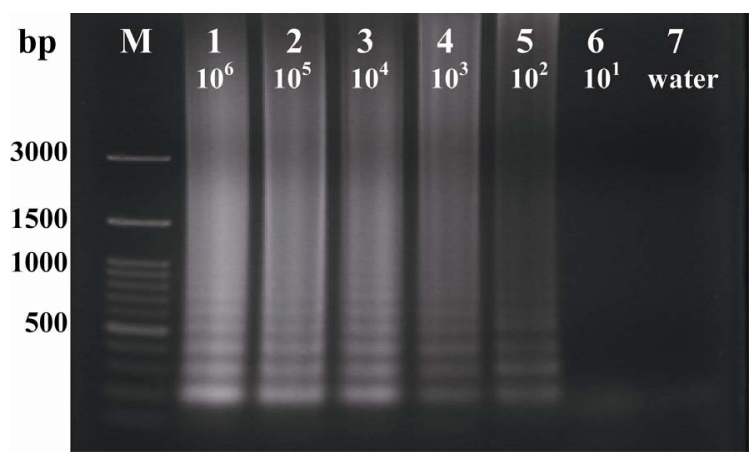

Figure 2. Sensitivity of LAMP was analyzed by agarose gel electrophoresis. Lane M: 100 bp DNA ladder, Lane 1-6: Serial 10-fold dilutions of recombinant plasmid $10^{6}$ to 10 copies/tube, respectively and Lane 7: RNase free water (negative control).

\begin{tabular}{|c|c|c|c|c|c|c|}
\hline$\underset{10^{6}}{1}$ & $\begin{array}{l}2 \\
10^{5}\end{array}$ & $\begin{array}{c}3 \\
10^{4}\end{array}$ & $\begin{array}{l}4 \\
10^{3}\end{array}$ & $\begin{array}{c}5 \\
10^{2}\end{array}$ & $\begin{array}{l}6 \\
10^{1}\end{array}$ & $\begin{array}{c}7 \\
\text { water }\end{array}$ \\
\hline 17 & 17 & - & - & - & - & - \\
\hline
\end{tabular}

Figure 3. Sensitivity of LAMP was analyzed by visualizetion HNB dye. Tube 1-6: Serial 10-fold dilutions of recombinant plasmid $10^{6}$ to 10 copies/tube, respectively and Tube 7: RNase free water (negative control).

\subsection{Specificity of CSFV RT-LAMP Assay}

Analytical cross-reaction of CSFV RT-LAMP assay with other pig disease viruses consisted of JEV and PRRSV. Viral RNA was used as template in this specificity test. The cross-reactions of RT-LAMP with RNA of JEV and PRRSV were carried out. In this study, the RT-LAMP assay detected CSFV from a hog-cholera live vaccine, revealing the characteristic ladder-like pattern in the gel (Figure 4) and color changes from violet to sky blue after the addition of HNB dye (Figure 5). No ladder-like pattern or color changes of HNB dye was observed for JEV, PRRSV and RNase free water. This result revealed that the RT-LAMP assay has a high specificity for CSFV.

\section{DISCUSSIONS}

Classical swine fever virus (CSFV), a member of the Pestivirus genus causes a highly contagious febrile disease worldwide. Outbreaks of CSF cause heavy losses in pig production and severely hamper the international trade in livestock [1]. Previous studies have been reported that CSFV and PRRSV may cause disease with similar clinical symptoms [26]. Additionally, CSFV co-infection with PRRSV played an important role in

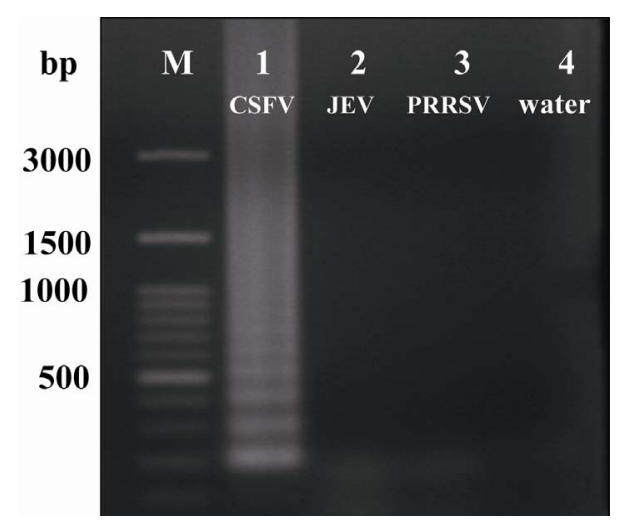

Figure 4. Specificity of RT-LAMP products visualized with agarose gel electrophoresis. Lane M: 100 bp DNA ladder, Lane 1: CSFV, Lane 2: JEV, Lane 3: PRRSV and Lane 4: RNase free water.

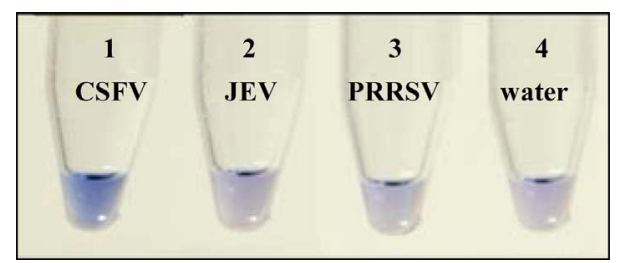

Figure 5. Specificity of RT-LAMP products visualized with HNB dye. Tube 1: CSFV, Tube 2: JEV, Tube 3: PRRSV and Tube 4: RNase free water. 
reproducing typical post weaning multisystemic wasting syndrome [27]. Taxonomically, JEV belongs to the same Flaviviridae family as CSFV [20]. Therefore, the development of a simple and rapid diagnostic tool that can detect CSFV and differentiae it from PRRSV in the same samples would be of significant importance in the epidemiologic surveillance and the prediction of severity of economically important viral diseases in swine herds.

It is very important to find a conserved nucleic acid fragment to design specific RT-LAMP primers. In this study, the nucleic acid sequence of 33 CSFV in GenBank was analyzed with the CLUSTALW multiple sequence alignment programs. The most conserved of 445 bp was found in the 5' untranslated gene which appeared highly conserved. The CSFV primers for RT-LAMP and RT-PCR targeting the conserved sequence of 5' untranslated genes were designed successfully with the Primer Explorer V4 software program and Primer3 Input (version 0.4.0) program, respectively. The RT-LAMP assay is a simple diagnostic tool in which the reaction is carried out in a single tube by a mixing of the buffer, primers, reverse transcriptase, and DNA polymerase, and incubating the mixture at $65^{\circ} \mathrm{C}$ for $60 \mathrm{~min}$. Besides, the higher amplification efficiency of the RT-LAMP reaction yields a large amount of a by-product, pyrophosphate ion, leading to white precipitate of magnesium pyrophosphate in the reaction mixture. Since the increase in the turbidity of the reaction mixture according to the production of precipitate correlates with the amount of the DNA synthesized, monitoring of the RT-LAMP reaction can be achieved with the naked eye or in a real-time with a turbidimeter [14]. Another useful feature was that RT-LAMP products could be directly observed by the addition of hydroxynaphthol blue (HNB) dye to the amplified products. Therefore, this technique is effective due to the high specificity and amplification efficiency, and may facilitate the application of RT-LAMP, especially in the field.

The results revealed that RT-LAMP assay detected at least 100 copy numbers of recombinant plasmid. Furthermore, the specificity of CSFV RT-LAMP did not show cross-reactivity with JEV and PRRSV, suggesting that this method is highly specific among the viral strains used in this study. The higher sensitivity and specificity of the RT-LAMP reaction were attributed to its continuous amplification under the isothermal conditions employing six primers that recognized eight distinct regions of the target.

\section{CONCLUSIONS}

Our studies presented the developed RT-LAMP assay is an extremely rapid, cost-effective, sensitive, and specific method for the detection of CSFV RNA. The me- thod requires only simple conditions and less time to obtain a result using the HNB dye, compared with the traditional gel electrophoresis. Therefore, the assay is more suitable for use under field conditions for rapid diagnosis of CSFV, which would allow emergency control measures to be implemented to prevent spread of infection.

\section{ACKNOWLEDGEMENTS}

We are thank Department of Biology Faculty of Science Silpakorn University and Department of Immunology Faculty of Medicine Siriraj Hospital Mahidol University, Omnoisophonchanupathom school, The Institute for the Promotion of Teaching Science and Technology, Thailand Research Fund (TRF no. DIG 5180004), Partial fund from MRG-WII525S092 and RGP 2552-06 for the financial supports, Department of Livestock Development, Ministry of Agriculture and Cooperatives for CSFV Bangkhen strain. We also thank to Dr. Pahol Kosiyachinda for reviewing the manuscript, Miss Siriporn Kaewklom for photographing.

\section{REFERENCES}

[1] Edwards, S., Fukusho, A., Lefèvre, P.C., Lipowski, A., Pejsak, Z., Roehe, P. and Westergaard, J. (2000) Classical swine fever: The global situation. Veterinary Microbiology, 73, 103-119. doi:10.1016/S0378-1135(00)00138-3

[2] Lowings, P., Ibata, G., Needham, J. and Paton, D. (1996) Classical swine fever virus diversity and evolution. Journal of General Virology, 77, 1311-1321. doi:10.1099/0022-1317-77-6-1311

[3] Stadejek, T., Vilcek, S., Lowings, J.P., Pordany, A.B., Paton, D.J. and Belak, S. (1997) Genetic heterogeneity of classical swine fever virus in Central Europe. Virus Research, 52, 195-204. doi:10.1016/S0168-1702(97)00118-4

[4] Kaden, V., Lange, E., Müller, T., Teuffert, J., Teifke, J.P and Riebe, R. (2006) Protection of gruntlings against classical swine fever virus-infection after oral vaccination of sows with C-strain vaccine. Journal of Veterinary Medicine, Series B, 53, 455-460. doi:10.1111/j.1439-0450.2006.00993.x

[5] Suradhat, S., Kesdangsakonwut, S., Sada, W., Buranapraditkun, S., Wongsawang, S. and Thanawongnuwech, R. (2006) Negative impact of porcine reproductive and respiratory syndrome virus infection on the efficacy of classical swine fever vaccine. Vaccine, 24, 2634-2642. doi:10.1016/j.vaccine.2005.12.010

[6] Damrongwatanapokin, S., Pinyochon, W., Parchariyanon, S. and Inui, K. (1999) Classical Swine Fever and Emerging Diseases in Southeast Asia. Proceedings of an International Workshop of the Australian Centre for International Agricultural Research, 94, 109-110.

[7] Paton, D.J., McGoldrick, A., Greiser-Wilke, I., Parchariyanon, S., Song, J.Y., Liou, P.P., Stadejek, T., Lowings, J.P., BjoÈrklund, H. and BelaÂk, S. (2000) Genetic typ- 
ing of classical swine fever virus. Veterinary Microbiology, 73, 137-157. doi:10.1016/S0378-1135(00)00141-3

[8] Moennig, V., Niesmann, G.F. and Wilke, I.G. (2003) Clinical signs and epidemiology of classical swine fever. The Veterinary Journal, 165, 11-20 doi:10.1016/S1090-0233(02)00112-0

[9] Clavijo, A., Zhou, E.M., Vydelingum, S. and Heckert, R. (1998) Development and evaluation of a novel antigen capture assay for the detection of classical swine fever virus antigens. Veterinary Microbiology, 60, 155-168. doi:10.1016/S0378-1135(98)00160-6

[10] Zupancić, Z., Jukić, B., Lojkić, M., Cac, Z., Jemersić, L. and Staresina, V. (2002) Prevalence of antibodies to classical swine fever, Aujeszky's disease, porcine reproductive and respiratory syndrome, and bovine viral diarrhoea viruses in wild boars in Croatia. Journal of Veterinary Medicine, Series B, 49, 253-256. doi:10.1046/j.1439-0450.2002.00562.x

[11] Risatti, G.R., Callahan, J.D., Nelson, W.M. and Borca, M.V. (2003) Rapid detection of classical swine fever virus by a portable real-time reverse transcriptase PCR assay. Journal of Clinical Microbiology, 41, 500-505. doi:10.1128/JCM.41.1.500-505.2003

[12] Handel, K., Kehler, H., Hills, K. and Pasick, J. (2004) Comparison of reverse transcriptase polymerase chain reaction, virus isolation, and immunoperoxidase assays for detecting pigs infected with low, moderate, and high virulent strains of classical swine fever virus. Journal of Veterinary Diagnostic Investigation, 16, 132-138. doi:10.1177/104063870401600207

[13] Notomi, T., Okayama, H., Masubuchi, H., Yonekawa, T., Watanabe, K., Amino, N. and Hase, T. (2000) Loop mediated isothermal amplification of DNA. Nucleic Acids Research, 28, e63. doi:10.1093/nar/28.12.e63

[14] Mori, Y., Nagamine, K., Tomita, N. and Notomi, T. (2001) Detection of loop-mediated isothermal amplification reaction by turbidity derived from magnesium pyrophosphate formation. Biochemical and Biophysical Research Communications, 289, 150-154. doi:10.1006/bbrc.2001.5921

[15] Pham, H.M., Nakajima, C., Ohashi, K. and Onuma, M. (2005) Loop-mediated isothermal amplification rapid detection of Newcastle disease virus. Journal of Clinical Microbiology, 43, 1646-1650.

[16] Iwamoto, T., Sonobe, T. and Hayashi, K. (2003) Loopmediated isothermal amplification for direct detection of Mycobacterium tuberculosis complex, M. avium, and $M$. intracellulare in sputum samples. Journal of Clinical Microbiology, 41, 2616-2622. doi:10.1128/JCM.41.6.2616-2622.2003

[17] Hong, T.C., Mai, Q.L., Cuong, D.V., Parida, M., Minekawa, H., Notomi, T., Hasebe, F. and Morita1 K. (2004) Development and evaluation of a novel loop-mediated isothermal amplification method for rapid detection of severe acute respiratory syndrome coronavirus. Journal of Clinical Microbiology, 42, 1956-1961.

[18] Parida, M.M., Santhosh, S.R., Dash, P.K., Tripathi, N.K., Saxena, P., Ambuj, S., Sahni, A.K., Lakshmana Rao, P.V. and Morita, K. (2006) Development and evaluation of reverse transcription-loop-mediated isothermal amplification assay for rapid and real-time detection of Japanese encephalitis virus. Journal of Clinical Microbiology, 44, 4172-4178. doi:10.1128/JCM.01487-06

[19] En, F.X., Wei, X., Jian, L. and Qin, C. (2008) Loop-mediated isothermal amplification establishment for detection of pseudorabies virus. Journal of Virological Methods, 151, 35-39. doi:10.1016/j.jviromet.2008.03.028

[20] Chen, H.T., Zhang, J., Ma, L.N., Ma, Y.P., Ding, Y.Z., Liu, X.T., Chen, L., Ma, L.Q., Zhang, Y.Q. and Liu, Y.S. (2009) Rapid pre-clinical detection of classical swine fever by reverse transcription loop-mediated isothermal amplification. Molecular and Celularl Probes, 23, 71-74. doi:10.1016/j.mcp.2008.12.001

[21] Yin, S., Shang, Y., Zhou, G., Tian, H., Liu, Y., Cai, X. and Liu, X. (2010) Development and evaluation of rapid detection of classical swine fever virus by reverse transcription loop-mediated isothermal amplification (RTLAMP). Journal of Biotechnology, 146, 147-150. doi:10.1016/j.jbiotec.2009.11.006

[22] Zhang, X.J., Sun, Y., Liu, L., Belák, S. and Qiu, H.J. (2010) Validation of a loop-mediated isothermal amplification assay for visualised detection of wild-type classical swine fever virus. Journal of Virological Methods, 167, 74-78. doi:10.1016/j.jviromet.2010.03.013

[23] Gachon, C., Mingam, A. and Charrier, B. (2004) Real-time PCR: What relevance to plant studies. Journal of Experimental Botany, 55, 1445-1454. doi:10.1093/jxb/erh181

[24] Ito, A. and Ueno, K. (1970) Successive chelatometric titration of calcium and magnesium using hydroxy naphthol blue (HNB) indicator. Japan Analyst, 19, 393-397.

[25] Goto, M., Honda, E., Ogura, A., Nomoto, A. and Hanaki, K. (2009) Colorimetric detection of loop mediated isothermal amplification reaction by using hydroxy naphthol blue. Bio Techniques, 46, 167-172. doi: $10.2144 / 000113072$

[26] Krumbholz, A., Wurm, R., Scheck, O., Birch-Hirschfeld, E., Egerer, R., Henke, A., Wutzler, P. and Zell, R. (2003) Detection of porcine teschoviruses and enteroviruses by LightCycler real-time PCR. Journal of Virological Methods, 113, 51-63. doi:10.1016/S0166-0934(03)00227-1

[27] Rovira, A., Balasch, M., Segales, J., Garcia, L., Plana-Duran, J., Rosell, C., Ellerbrok, H., Mankertz, A. and Domingo, M. (2002) Experimental inoculation of conventional pigs with porcine reproductive and respiratory syndrome virus and porcine circovirus 2. Journal of Virology, 76, 3232-3239. 